\title{
Sistemas de Informação na Saúde: Uma Aplicação do "Customer Relationship Management" (CRM) em uma Pulmoclínica
}

\author{
Margarete Kraus ${ }^{1}$, Oscar Dalfovo ${ }^{2}$, \\ 1, Faculdade Instituto Blumenauense de Ensino Superior - IBES \\ Rua: Pandiá Calógeras, 272 CEP: 89010-350 - Santa Catariana-SC / Brasil \\ maggue@pop.com.br \\ ${ }^{2}$ Faculdade Instituto Blumenauense de Ensino Superior (IBES), \\ Universidade Regional de Blumenau (FURB) / Universidade Federal de Santa Catarina (UFSC) \\ Rua: Pandiá Calógeras, 272 CEP: 89010-350 - Santa Catariana-SC / Brasil \\ dalfovo@egc.ufsc.br / dalfovo@furb.br
}

\begin{abstract}
Resumo
Este trabalho aborda a necessidade de reestruturação do gerenciamento do relacionamento com o cliente em clínica de pulmão. O objetivo deste trabalho é aplicar o Costumer Relationship Management (CRM) na Pulmoclínica, para identificação do perfil do cliente e personalização do atendimento. A metodologia utilizada foi um estudo de avaliação, que consistem nos estudos quantitativos e descritivos que se relacionam a procura dos efeitos e resultados. Os resultados alcançados foram que a implantação do CRM permite conhecer melhor o cliente consumidor e aprimora seu relacionamento. Conclui-se que é de suma importância a aplicação de um método para a fidelização do atendimento.
\end{abstract}

Palavras-chave: Relacionamento, Saúde, Personalização, Fidelização.

\begin{abstract}
The work approaches the need of restructuring of the administration of the relationship with the customer in lung clinic. The objective of this work is to apply Costumer Relationship Management (CRM) in Pulmoclínica, for identification of the customer's profile and personalização of the attendance. The used methodology was an evaluation study, that you/they consist of the quantitative and descriptive studies that link the search of the effects and results. The reached results were that the implantation of CRM allows to know the consuming customer better and it perfects your relationship. It is ended that is of highest importance the application of a method for the fidelização of the attendance.
\end{abstract}

Key words: Relationship, Health, Personalizing

\section{Introdução}

Em decorrência da evolução tecnológica na área da informática, a Internet obteve destaque crescente e significativo nos últimos anos, e com isso, os vários setores da economia e da sociedade em geral, inclusive o setor corporativo precisou se aperfeiçoar continuamente para acompanhar esse crescimento da Internet. Nesse contexto, observou-se a necessidade de rever alguns conceitos e se reestruturar, não bastando oferecer produtos e serviços com melhor qualidade e preço, foi preciso criar alternativas para incrementar a gerência do relacionamento com o cliente de forma a não perdê-lo para a concorrência.
Desse modo, ao se pensar em saúde, é relevante pensar em medidas e propostas que contemplem a elaboração de políticas fundamentais no acompanhamento e análise das condições de atendimento à saúde da clientela.

Embora as pesquisas de mercado realizadas por muitas empresas, para obter dados sobre os consumidores, representem uma importante ferramenta na identificação do perfil do cliente, as pessoas em geral não sabem expressar o que de fato desejam, dificultando a fidelização e o apoio eficaz à criação de mercado.

Com a criação da Pulmoclínica em 1999, a cidade de Blumenau passou a contar com uma empresa que facilitava o acesso da comunidade a um serviço de 
pneumologia moderno dentro de um hospital. Hoje, a empresa é responsável por todo o serviço de nebulização dos pacientes internados no Hospital Santa Catarina. Em conexão com o setor empresarial, a Pulmoclínica desenvolve uma série de exames pulmonares, buscando a preservação e saúde dos colaboradores que aderem ao Programa de Controle Médico de Saúde Ocupacional. Ainda oferece uma série de outros serviços como: vacinas contra a gripe, pHmetria, espirometria (provas de função respiratória), broncoscopia, fisioterapia respiratória, testes alérgicos, aerossolterapia e tratamento intensivo ambulatorial.

A Pulmoclínica conta em seu quadro funcional com atendentes administrativos, enfermeiros, técnicos de enfermagem, profissionais da área de fisioterapia e médicos capacitados. Esses profissionais estão em constante atualização, pois, o alvo comum a todas as organizações é de gerar soluções para as necessidades de seus clientes. Para que isso aconteça, é necessário contar com técnicas e ferramentas que permitam identificar o perfil do cliente, bem como medir e monitorar esses requisitos. A satisfação do cliente, em conjunto com a melhoria contínua do relacionamento com o cliente torna-se os objetivos mais importantes de qualquer sistema de gestão.

Nesse contexto, observa-se que possuir tecnologia e oferecer os melhores serviços são atitudes e características imprescindíveis para o sucesso das empresas modernas.

Embora a Constituição Federal estabeleça que a "saúde é um direito de todos e dever do Estado", em decorrência da explosão populacional ocorrida nas últimas décadas, observa-se que a viabilização dos recursos não é suficiente para atender a crescente demanda e esses fatores aliados a falta de profissionais na rede pública de saúde, são fatores que levam uma parcela significativa da população a migrar para os planos privados de saúde, buscando melhor atendimento nos serviços credenciados por esses planos. As organizações existem para gerar resultados e o melhor resultado advém da estratégia que permite à empresa como um todo ter uma visão única de seu cliente e, a partir daí, identificar, interagir, criar uma relação de aprendizado contínuo. Nesse sentido, a relevância científica dessa investigação é importante não só para os usuários, mas também para os administradores de clínicas de pulmão. Atingir a ótima administração de suas ações garante as prestadoras de serviços mais recursos para projetos capazes de registrar todas as informações relativas a esse relacionamento do cliente com a empresa, ou seja, quando o cliente liga, para que ele seja reconhecido e a empresa possa aproveitar esse momento, oferecendo serviços que se afinem com o perfil daquela pessoa em particular.

Qual a contribuição da administração do Customer Relationship Management - CRM, no apoio a identificação do perfil do cliente na Pulmoclínica, de Blumenau?

Aplicar o Customer Relationship Management (CRM) na Pulmoclínica- Clínica Gabriela Menezes Lopes SS Ltda, de Blumenau para identificação do perfil do cliente e personalização do atendimento. Mais especificamente são: a) Identificar o perfil do cliente consumidor da Pulmoclínica; b) Analisar como se dá a comunicação entre o cliente consumidor e a Pulmoclínica; c) Apresentar as informações do perfil do cliente, para auxiliar à Pulmoclínica, no direcionamento do atendimento ao cliente; d) Plano de implantação de um call center - CRM.

Em decorrência da rápida evolução e mudanças tecnológicas, os executivos devem ser versáteis em suas decisões, mas, para isso, devem ter em mãos informações exatas e em tempo real. Os Sistemas de Informação surgiram para que o executivo se mantenha atualizado, tenha uma visão sistêmica da empresa, tudo isso em menor espaço de tempo possível [7].

O processo de utilização orientada da informação iniciou a partir de 1985, onde, as informações começarem ser consideradas como commodity em decorrência do sentido e papel a elas atribuídas pelas organizações. As funções administrativas começaram a ser tratadas de maneira individualizada, resultando na criação de inúmeras informações, com o objetivo de auxiliar nas funções administrativas e gerenciais dos executivos nos diversos níveis hierárquicos nas tomadas de decisões [16].

Nesse contexto, o conceito sustenta que a partir de 1985, as organizações basearam suas atividades nas informações, que passaram de meros dados funcionais a um mecanismo aliado, assumindo estrategicamente em tempo real, o instrumento que norteia os executivos na tomada de decisões. Ao mesmo tempo, resultou na individualização das informações de forma a atender os diversos níveis hierárquicos existentes na empresa, proporcionando a seus executivos uma visão sistêmica denominada visão orientada do todo, no qual fazem parte [14].

A economia globalizada está mais dependente da administração e distribuição de recursos de informação para redes globais interconectados como a Intranet. Dessa forma, muitas companhias estão no processo de globalização, ou seja, estão se tornando empreendimentos globais interconectados. As empresas estão se expandindo, por exemplo, para mercados globalizados para venderem seus produtos e serviços, utilizando instalações de produção globalizada para fabricar ou montar produtos, obter recursos em mercados mundiais de capital, formando alianças como parceiros globais e competitivos com concorrentes globais [14].

Em relação aos conceitos básicos, pode-se destacar os comportamentais, técnicos e administrativos em relação aos componentes e papéis dos sistemas de informação. Quanto às suas aplicações empresariais, estas ocorrem no contexto da utilização dos sistemas de informação para as operações, administração e vantagem competitiva de um empreendimento, utilizando intranets, internets e extranets. Os desafios gerenciais abrangem os desafios de administrar de forma efetiva e ética, os recursos e estratégias de negócios envolvidos na utilização da tecnologia da informação considerando o usuário final, o empreendimento e o aspecto globalizado do negócio [14]. 
Um sistema de informação é um conjunto organizado de pessoas, hardware, software, redes de comunicações e recursos de dados que absorve, transforma os dados em informação na organização como um todo. Esses sistemas permitem a comunicação, utilizando os dispositivos físicos (hardware), instruções e procedimentos de processamento de informações (software), canais de comunicações (redes) e dados armazenados (recursos de dados) [14].

No contexto dos sistemas de informações, a entrada é a atividade de reunião e coleta de dados brutos que se apresentam de várias formas podendo ser manual ou automatizada. $\mathrm{O}$ método utilizado deverá permitir que o sistema alcance a saída desejada. Da mesma forma, o processamento poderá ser feito manualmente ou com a ajuda de computadores (impressoras e monitores), transformando a informação em saídas úteis, através de documentos e relatórios. O feedback é a saída utilizada para promover as mudanças na entrada ou nas atividades de processamento. [17].

O ser humano entende por informação, tudo que é atribuído a um determinado dado, sejam as informações desempenhadas por convenções ou representações. Exemplo disso é o semáforo para regular o trânsito, onde a informação está implícita através das cores verde que indica seguir, amarelo indica ter atenção, vermelho indica parar. Dessa forma, toda a informação deve gerar uma decisão que, por sua vez desencadeará uma ação [6].

Em toda a atividade exercida pelo ser humano e o meio em que vive, é um processo permanente de informação. Para as organizações é imprescindível ter informação, pois constitui a base para o conhecimento dos problemas, buscar alternativas para solucioná-los, atingir metas e cumprir objetivos, ficando impossibilitado gerenciar setores caso não haver um sistema de apoio à decisão, que tenha como base a informação [8].

Da mesma forma, a informação em saúde deve ser entendida como um sistema de apoio decisório para o conhecimento da realidade social que hoje se vive, bem como sua demografia e fatores epidemiológicos, para o planejamento, gestão, organização e avaliação nos vários níveis que constituem os Sistemas de Saúde [6].

O problema da saúde no Brasil não será solucionado, enquanto não houver a integração entre os setores públicos e privados atuando em programas de prevenção e assistência única para todos os cidadãos brasileiros. Uma das formas capazes de garantir essa integração dos setores é a utilização da informação e comunicação [13].

Em decorrência do grande volume de informações, a utilização da informática viabiliza, de forma rápida e segura, a manipulação, acesso, recuperação e processamento, assistência e administração de serviços de saúde. No Brasil, a presença de servidores de informação em saúde na Internet é crescente, mas ainda pouco significativa [13].

A tecnologia da informação (TI) é definida como um conjunto de todas as atividades e soluções providas por recursos de computação, onde, as aplicações para TI estão ligadas às mais diversas áreas que existem várias definições e nenhuma consegue determiná-la por completo. A informação agrega valores a uma empresa ou a um indivíduo, sendo necessário fazer uso de recursos de TI de maneira apropriada, ou seja, é preciso utilizar ferramentas, sistemas ou outros meios que façam das informações um diferencial competitivo. Além disso, é necessário buscar soluções que tragam bons resultados, mas que tenham o menor custo possível [1].

Alguns componentes da tecnologia da informação podem ser definidos como hardware, software, redes, administração de banco de dados e outras tecnologias do processamento da informação em busca de vantagem competitiva [14].

As organizações são beneficiadas pela TI, através da sua capacidade de melhorar a qualidade e a disponibilidade de informações e conhecimentos importantes para a empresa, seus clientes e fornecedores. Os sistemas de informação modernos oferecem às empresas oportunidades que visam a melhoria dos processos internos e dos serviços prestados ao consumidor. Essa tecnologia permeia a cadeia de valor, transformando a maneira como as atividades são executadas e a natureza das interligações entre elas, afetando o escopo competitivo e reformulando a maneira como os produtos e serviços atendem às necessidades dos clientes. Estes efeitos básicos explicam porque a tecnologia da informação adquiriu um significado estratégico e diferencia-se de muitas outras tecnologias utilizadas nos negócios [5].

A tecnologia da informação está redefinindo os fundamentos dos negócios como atendimento ao cliente, operações, estratégias de produto e marketing. A tecnologia da informação pode dar suporte a todos os tipos de empresas a melhorarem a eficiência e eficácia de seus processos empresariais, fortalecendo a tomada de decisões, bem como colaborar com os grupos de trabalho. Com a era da Internet, as empresas estão aprimorando as suas tecnologias e sistemas de informações, tornando-os ingredientes imprescindíveis e garantia de sucesso ao cenário competitivo e globalizado dos negócios [14].

O desenvolvimento e aplicação das novas tecnologias de informação (TI) podem ser observados através das grandes tendências que direcionam o desenvolvimento das TIs e novas tecnologias que são integradas ou encontram resistências nos ambientes corporativos e empresariais onde são aplicadas. O papel da Internet é fundamental, tanto do ponto de vista do seu impacto sobre a economia quanto da sua importância como uma das principais mídias fornecedoras de informação, conhecimento e interpretações sobre o universo das TIs [11].

Até pouco tempo, eram raras as instituições que se preocupavam em implementar segurança em suas redes e sistemas de informação, mas diante da publicidade criada em torno dos ataques de vírus e hackers a sistemas de todos os tamanhos, esse assunto atraiu a atenção dos executivos, onde, muitas empresas passaram a incluir a proteção da informação entre as questões estratégicas da corporação. Essa preocupação é 
totalmente justificada, em virtude da dependência das empresas em relação à tecnologia da informação, a qual tem aumentado numa significativa velocidade [2].

Esse tema inicialmente é abordado através da introdução do assunto relacionado à inteligência competitiva, onde, esta pode ser definida como um programa institucional sistemático para garantir e analisar informação sobre as atividades da concorrência e as tendências do setor específico e do mercado em geral, com o propósito de levar a organização a atingir seus objetivos e metas. As principais características são implantação de departamento de inteligência competitiva (IC) ao cliente, incluindo treinamentos, documentações e infra-estrutura de hardware e software, implantação do software Cortex Competiva para suporte às operações de IC, terceirização para atividades e processos de IC, terceirização de infra-estrutura e terceirização de consultores de IC. Os benefícios esperados abrangem a identificação dos pontos fortes e fracos de concorrentes específicos, previsão das ações estratégicas dos concorrentes, aperfeiçoamento de estratégias, posicionamento, operações e desempenho financeiro, vencer os concorrentes no âmbito dos prérequisitos de sucesso sobre clientes e canais de distribuição, aprender com os erros dos concorrentes [10].

Em decorrência do mercado globalizado e em constante mutação, aumentou a concorrência entre as empresas e isso tem tornado os clientes cada vez mais exigentes. Os produtos e serviços de alta qualidade a preços cada vez mais baixos são comodities e fazem parte da filosofia da maioria das empresas que sobreviveram à década de $90 \mathrm{com}$ a sua imensa onda de fusões e aquisições e mudança de core business para adaptar-se às novas condições competitivas. Porém, colocar o foco no cliente para manter uma vantagem competitiva sustentável é necessário dar um salto qualitativo na prática do Marketing através de estratégia e tecnologia que ofereçam informações para que a tomada de decisão e a gestão concentrem-se nos momentos da verdade, em que os clientes vivenciam a negociação e o atendimento [4].

Nos últimos anos, muitas empresas não obtiveram sucesso no intento de encantar o cliente, mesmo diante de grandes gastos em comunicação, na implantação de Contact Centers adotando técnicas como o telemarketing e de e-business para venda ou atendimento ao cliente, pois não dispunham de tecnologia e de processos que permitissem gerenciar o relacionamento com o cliente, incorporando as informações a partir de qualquer tipo de contato ao longo do ciclo de atendimento ao cliente (vendas ou qualquer outro tipo de solicitação). E, mesmo tendo a tecnologia de CRM negligenciam o uso inteligente da informação pela organização atendo-se a práticas ultrapassadas de gestão. Assim, concluímos que o principal fator de sucesso da filosofia de Marketing de Relacionamento consiste na integração interfuncional dos seus quatro pilares: filosofia, processo, tecnologia e pessoas, evitando-se o encapsulamento da nova mentalidade em relação à importância do cliente nos departamentos chamados de linha de frente, que na maioria das vezes enfrentam grandes conflitos interdepartamentais para cumprir suas metas [3].

O conceito de CRM (Customer Relationship Management), vem sendo amplamente citado no ambiente de negócios como uma forma de obtenção de vantagem competitiva. Vantagem essa que tem sido amplamente anunciada por empresas de consultoria e softwarehouses, enquanto desponta no meio acadêmico a preocupação se é o CRM uma "nova grande idéia", agindo no mercado como uma forma oportunista para impulsionar vendas, ou se, realmente, o CRM tem respaldo acadêmico e possui um papel fundamental no ambiente de negócios. $\mathrm{O}$ que se pode afirmar é que o CRM é uma estratégia empresarial, apoiada no marketing de relacionamento e tecnologia da informação [9].

O relacionamento com o cliente é uma das principais vantagens competitivas sustentáveis possíveis de se construir por uma empresa. Um relacionamento duradouro, com elementos como fidelidade e confiança, é um recurso difícil de ser construído e mantido, então, esse é o pressuposto da estratégia de CRM, ou seja, basear-se no conhecimento, para fidelizar o cliente, permitindo que a empresa mantenha com ele um relacionamento de longo prazo. Para tanto, faz-se necessário, além de formular a estratégia, saber lidar com as competências e capacidades internas da organização. O CRM pode ser visto como a estratégia que põe em prática os princípios do Marketing de Relacionamento. Esse, que pode ser definido como todas as atividades de marketing direcionadas a estabelecer, desenvolver, e manter trocas relacionais de sucesso [15].

\section{$2 \quad$ Metodologia}

Neste capítulo estão expostos os procedimentos metodológicos adotados na preparação do trabalho em questão, bem como as técnicas e critérios, a fim de obter respostas à questão e alcançar os objetivos propostos.

Um dos objetivos da pesquisa é investigar e estudar o mundo e suas transformações, atendendo ao desejo do ser humano de se conhecer e a realidade circundante. Nessa tarefa, confronta-se com todas as forças da natureza e consigo mesmo, usando as forças intelectuais e sensoriais, organiza as possibilidades de agir e seleciona todo o instrumental necessário ao sucesso de seu empreendimento (NASCIMENTO, 2002).

$\mathrm{Na}$ Modalidade de pesquisa - Atualmente a pesquisa realizada em saúde destina-se a estudar e compreender determinado grupo de pessoas e a relação saúde/doença. Com a crescente procura por atendimento público em saúde, os gestores devem buscar com as investigações, a solução dos problemas e também amenizar o impacto financeiro resultante dessas ações.

Para alcançar os fins a que se propunha o projeto de estágio, foi utilizado um estudo de avaliação, que consistem nos estudos quantitativos e descritivos [12] que dizem respeito à procura dos efeitos e resultados de todo um programa ou método específico de atividades 
de serviço ou auxílio. As hipóteses podem ou não estar explicitamente declaradas e com freqüência derivam dos objetivos do programa ou método que está sendo avaliado.

Quanto aos objetivos, a pesquisa se caracteriza como exploratória, pois permite um aprofundamento sobre temas e questões com as quais o pesquisador não esteja ainda muito familiarizado, criando as condições de formulação de hipóteses.

Para busca de levantamento dos dados coletados, baseado em dados secundários e internos da Pulmoclínica, da cidade de Blumenau, SC, Brasil, em 2006 e conseqüentemente analisados, descrevendo a realidade funcional que servirá de recursos para a proposta de soluções.

No Campo de observação - O presente estudo realiza-se integralmente na Pulmoclínica, localizada em Blumenau, sendo que o motivo pelo qual a pesquisa foi realizada em apenas um setor, está no fato de que este estudo visa conhecer o perfil do cliente, através da aplicação da ferramenta CRM, a fim de criar um atendimento personalizado à clientela.

Nos instrumentos de coletas de dados - As técnicas utilizadas para a coletar dados para uma pesquisa, advém das diversas formas como são aplicadas essas pesquisas como questionários e formulários, ou seja, a reunião do instrumental necessário à realização de uma pesquisa.

A etapa de elaboração e organização dos instrumentos de investigação e pesquisa é complexa, pois necessita tempo, ao mesmo tempo em que é uma etapa fundamental no planejamento da pesquisa em geral. As obras referentes a pesquisa científica oferecem esboço prático, auxiliando na orientação para a construção de formulário, roteiro de entrevista, escalas de opiniões ou de atitudes, assim como também, indica sobre o tempo e o material necessário para a realização de um estudo científico [12].

Esta pesquisa será realizada a partir dos dados primários coletados dos clientes atuais da Pulmoclínica.

Os Critérios para análise dos dados - A análise e interpretação dos dados serão de caráter pessoal e terá como base a revisão bibliográfica e o roteiro utilizado na coleta de dados, com uma transcrição dos dados coletados e agrupamento de respostas, visando similaridades e comparações, para então gerar um relatório final.

A Descrição das etapas da investigação foram: elaboração de um roteiro; aplicação; análise dos resultados; projeções; discussão do tema com o professor orientador; discussão do tema com o orientador de campo e com o diretor; redação do relatório final.

\section{$3 \quad$ Resultados}

Atualmente a pesquisa realizada em saúde destina-se a estudar e compreender determinado grupo de pessoas e a relação saúde/doença. Com a crescente procura por atendimento público em saúde, os gestores devem buscar com as investigações, a solução dos problemas e também amenizar o impacto financeiro resultante dessas ações.

Para alcançar os fins a que se propunha o projeto de estágio, foi utilizado um estudo de avaliação, que consistem nos estudos quantitativos e descritivos [12] que dizem respeito à procura dos efeitos e resultados de todo um programa ou método específico de atividades de serviço ou auxílio. As hipóteses podem ou não estar explicitamente declaradas e com freqüência derivam dos objetivos do programa ou método que está sendo avaliado.

Quanto aos objetivos, a pesquisa se caracteriza como exploratória, pois permite um aprofundamento sobre temas e questões com as quais o pesquisador não esteja ainda muito familiarizado, criando as condições de formulação de hipóteses.

Para busca de levantamento dos dados coletados, baseado em dados secundários e internos da Pulmoclínica, da cidade de Blumenau, SC, Brasil, em 2006 e conseqüentemente analisados, descrevendo a realidade funcional que servirá de recursos para a proposta de soluções.

O presente estudo realiza-se integralmente na Pulmoclínica, localizada em Blumenau, sendo que o motivo pelo qual a pesquisa foi realizada em apenas um setor, está no fato de que este estudo visa conhecer o perfil do cliente, através da aplicação da ferramenta CRM, a fim de criar um atendimento personalizado à clientela.

As técnicas utilizadas para a coletar dados para uma pesquisa, advém das diversas formas como são aplicadas essas pesquisas como questionários e formulários, ou seja, a reunião do instrumental necessário à realização de uma pesquisa.

A etapa de elaboração e organização dos instrumentos de investigação e pesquisa é complexa, pois necessita tempo, ao mesmo tempo em que é uma etapa fundamental no planejamento da pesquisa em geral. As obras referentes a pesquisa científica oferecem esboço prático, auxiliando na orientação para a construção de formulário, roteiro de entrevista, escalas de opiniões ou de atitudes, assim como também, indica sobre o tempo e o material necessário para a realização de um estudo científico.

A empresa Prestadora de Serviços Pulmoclínica Clínica Gabriela Menezes Lopes SS Ltda - é uma prestadora de serviços, que tem seu foco voltado para a saúde do pulmão e está localizada a Rua Dr. Armando Odebrecht, $70,5^{\circ}, 6^{\circ}$ e $7^{\circ}$ andar, Blumenau - SC. Sua estrutura é representada através do organograma abaixo e quadro funcional, onde representa as relações de autoridade e responsabilidade entre seus colaboradores. Com base na pesquisa realizada que constituiu-se de um questionário estruturado, contendo 13 questões objetivas, onde pretendeu-se obter informações referentes ao perfil do cliente, atendimento na clínica e meios de comunicação entre a empresa e os clientes.

A amostra do trabalho constituiu-se de 50 entrevistados, ou seja, $100 \%$ das pessoas atendidas mensalmente no período de fevereiro a abril/2006, 
porém, somente 33 pessoas responderam ao questionário, perfazendo um total de $66 \%$.

Na questão 1, "Qual o sexo do cliente consumidor da Pulmoclínica”, dos 33 respondentes, observou-se que os clientes consumidores da Pulmoclínica são em sua maioria do sexo feminino, perfazendo $61 \%$ da amostra, enquanto que $39 \%$ são do sexo masculino.

Na questão 2, "Qual a idade do cliente consumidor da Pulmoclínica", dos 33 respondentes, pode-se observar, através do gráfico 3 , que a idade dos clientes consumidores são em sua maioria entre 45 e 60 anos, ou seja, a maior demanda encontra-se nessa faixa etária, onde, há maior necessidade de aprimoramento e melhorias de forma constante nos vários setores da empresa envolvida nesse estudo.

$\mathrm{Na}$ questão 4, "Qual a escolaridade do cliente consumidor da Pulmoclínica", observou-se que dos 33 respondentes, dez dos clientes consumidores completaram o $2^{\circ}$ grau e seis pessoas possuem o diploma de nível superior. Observa-se também que sete respondentes são alfabetizados e 8 completaram o ensino fundamental.

"Indagados sobre a necessidade de receber um tratamento diferenciado por parte Pulmoclínica", conforme a questão 4, 30 pessoas responderam que até o presente momento não recebem tratamento diferenciado, enquanto que duas pessoas responderam que recebem. Um cliente optou por não responder essa questão. Essas informações obtidas serão de suma importância para podermos rever o atendimento ao cliente atualmente e posteriormente, aprimorar o atendimento ao cliente.

$\mathrm{Na}$ questão 5, "Você recebe um retorno perguntando se está tudo certo com o atendimento", dos 33 respondentes, pode-se verificar que o feedback existente entre a empresa e o cliente, é significativamente positivo, pois a maioria $52 \%$ dos clientes responderam que recebem esse feedback da empresa, mesmo após o atendimento na clínica, entretanto, observa-se que para $48 \%$ não há esse feedback, sendo importante o aprimoramento desse sistema de relação entre empresa e o cliente.

$\mathrm{Na}$ questão 6, "Como se dá a comunicação entre você cliente e a Pulmoclínica", no gráfico 1, observa-se que a comunicação dos clientes com a empresa é em sua maioria realizada através de telefone, 33 pessoas responderam que esse é o meio de comunicação que utilizam para estabelecer contato com a clínica em questão, enquanto que três pessoas comunicam-se através de e-mail. Para os outros meios de comunicação evidenciados no gráfico, não houve respondentes.

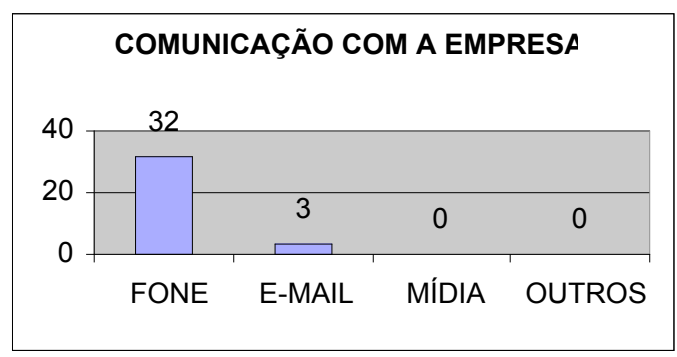

Gráfico 1 - Comunicação com a Empresa
"Indagados para o caso de a Púlmoclínica lançar uma propaganda de sua empresa, qual meio de comunicação tornaria mais fácil o acesso dos clientes a essa prestadora de serviço", conforme a questão 7, dos 33 respondentes, treze pessoas optaram para que a divulgação fosse feita através da televisão, uma vez que a maioria das pessoas utilizam esse veículo. Sete pessoas consideram que a revista da Unimed, através do recebimento em casa, é um excelente veículo de propagação da clínica. Cinco respondentes consideram importante a visita pessoal, três consideram que a colocação de outdoors na cidade chamaria a atenção para a clínica, enquanto que 2 pessoas optaram pelo rádio. Não houve nenhum respondente para a revista do Hospital Santa Catarina, conforme exposto no gráfico 2.

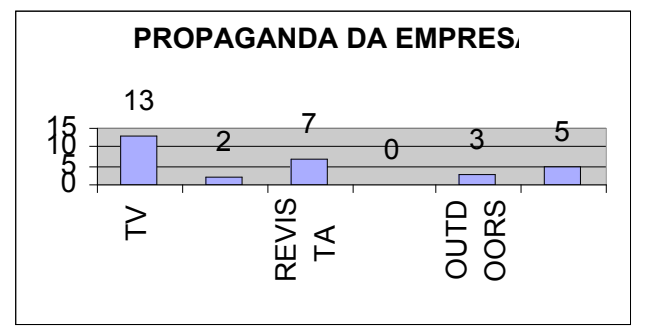

Gráfico 2 - Propaganda da Empresa

Na questão 8, "O atendimento se dá através de", diante do exposto, observou-se que 30 respondentes possuem plano de saúde, ou seja, a maioria dos atendimentos da clínica ocorre através dos convênios. Três responderam que utilizam o sindicato como via de acesso a clínica em questão. Não houve respondentes para o atendimento particular.

$\mathrm{Na}$ questão 9, "Você utiliza os serviços da Pulmoclínica com o objetivo de", dos 33 respondentes, 29 usuários dirigem-se à clínica para tratamento de doença crônica, sendo este o motivo porque procuram à clínica. Duas pessoas responderam que utilizam os serviços da clínica para consultas eventuais e duas pessoas responderam que utilizam os serviços para exames de rotina. Observa-se um nivelamento de clientes entre as categorias indicadas. Não houve nenhum respondente para os exames especializados, conforme exposto no gráfico 3 .

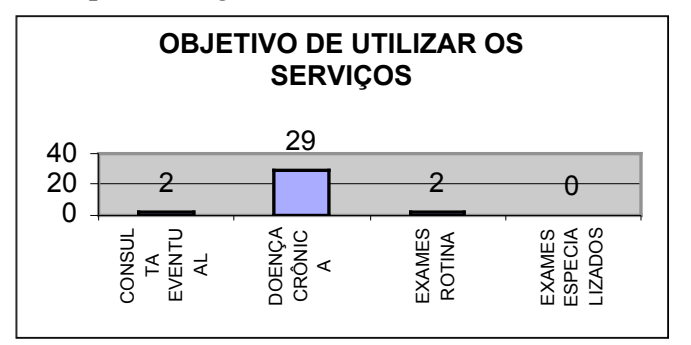

Gráfico 3 - Utilização dos Serviços

Na questão 10, "Com que freqüência você utiliza os serviços da Pulmoclínica", dez usuários utilizam os serviços da clínica mensalmente. Oito usuários são freqüentadores semestrais, sete pessoas responderam que utilizam no trimestre, três pessoas responderam que utilizam a cada dois meses e três pessoas responderam 
que utilizam anualmente. Apenas 1 cliente respondeu que utiliza os serviços da clínica em período semanal. Não houve nenhum respondente para a utilização quinzenal. Embora o período mensal tenha apresentado maior número de respondentes, pode-se verificar que a periodicidade de utilização dos serviços da clínica são variáveis onde, a maioria de seus clientes cadastrados, utilizam de forma mensal, trimestral e semestral, de acordo com a necessidade da patologia ou outro acometimento da saúde.

Já, "Indagados quanto à doenças concomitantes e fatores de risco", conforme exposto na questão 11, dos 33 respondentes, 32 responderam que não são portadores de necessidades especiais e também não são fumantes, uma pessoa respondeu ser portador de necessidades especiais e um é fumante, três dos entrevistados são diabéticos e 30 responderam que não. Oito são hipertensos e 25 não tem problemas com pressão arterial. Pode-se verificar que 16 pacientes estão acima do peso e 17 não estão acima do peso, conforme exposto no gráfico 4.

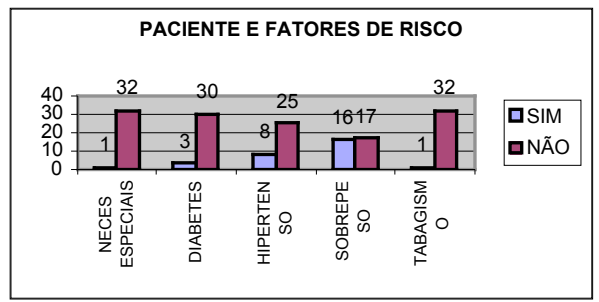

Gráfico 4 - Fatores de Risco

Em relação ao grau de aproveitamento, na questão 12, "Em relação ao atendimento em geral, oferecido atualmente, qual o grau de aproveitamento", observa-se que o atendimento é excelente para $67 \%$ dos respondentes e $33 \%$ responderam que é bom, entretanto, essas informações relatam que o atendimento é de boa qualidade, mas pode ser aprimorado para atender a demanda da clientela.

Para conhecermos o serviço de recepção da clínica desse estudo, elaborou-se uma pergunta sobre o assunto e obteve-se que dos serviços que estão a disposição dos clientes, questão 13, "Assinale os serviços que mais gosta de dispor na recepção/sala de espera da Pulmoclínica", dos 33 respondentes, treze pessoas preferem usufruir das revistas, doze preferem tomar café ou chá, sete respondentes optaram pela televisão enquanto aguardam o atendimento, quatro pessoas consideram ser primordial o atendimento efetuado pela recepcionista. Não houve nenhum respondente para música ou biscoitos oferecidos, conforme exposto no gráfico 5 .

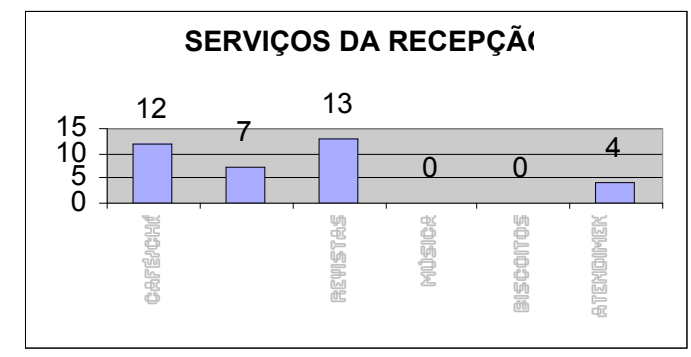

Gráfico 5 - Serviços da Recepção da Clínica
Conforme o objetivo específico, as informações apresentadas a respeito do perfil do cliente, para auxiliar a Pulmoclínica, no direcionamento do atendimento ao cliente, verificou-se que atualmente, o processo de relacionamento com o cliente acontece no pós atendimento, ou seja, é realizado contato com o cliente, para verificar como este se sente. A mesma metodologia é aplicada para os casos em que o paciente sofreu alguma intervenção cirúrgica.

São feitos contatos com os pacientes para lembrálos da data da consulta ou exame a ser realizado. Esse processo não está em funcionamento no momento. Também são feitas pesquisas internas de satisfação, através de questionário, que está a disposição do cliente na recepção da clínica, sendo do interesse do usuário responder o questionário ou não.

Há folder na recepção da clínica, que trata da localização e os exames oferecidos. Ressalte-se que a localização, conforme exposto no folder, dificulta o entendimento de novos entrantes ao acesso, mesmo porque esse folder encontra-se disponível internamente, ficando novamente a critério do paciente atual tornar-se ou não veículo propagador da clínica, através da disseminação do folder por vias externas.

O layout da empresa apresenta-se em 3 pavimentos do Centro Clínico Santa Catarina, ou seja, no $5^{\circ}, 6^{\circ}$ e $7^{\circ}$ andares, sendo que o atendimento a ser realizado ao paciente encontra-se nesses três andares, dificultando a comunicação interna entre os colaboradores, bem como para o próprio paciente que muitas vezes não sabe onde deve ser atendido.

A clínica não tem controle dos óbitos, já que os pacientes podem falecer em casa ou no hospital. A clínica tem conhecimento do fato, quando o hospital avisa ou quando os familiares do paciente entram em contato com o médico comunicando o falecimento. Em momento algum são realizados trabalho de busca desses clientes.

Quanto ao site existente www.pulmoclinica.com.br -, não há controle da quantidade de acessos executados e as informações disponíveis não são atualizadas periodicamente. Nenhum atendimento personalizado foi criado até o presente momento, para que o visitante queira voltar ao site.

A clínica, objeto do estudo em questão, não faz investimentos na área de propaganda externa, ou seja, não é utilizado os meios de comunicação de massa para promover seus produtos e serviços.

O sistema de informações (software) utilizado na clínica atualmente, é integrado; e consiste num banco de dados dos pacientes, onde se tem o cadastro desses pacientes e a evolução do seu tratamento. O agendamento de consultas também é efetuado nesse sistema.

Quanto as imagens de exames e seus respectivos resultados, que podem e devem ser fornecidos aos médicos, não são utilizados devido a incompatibilidade existente entre o sistema de informações da clínica e o software aplicado. 
A clínica está em processo inicial de palestras efetuadas em escolas do município. Há uma falha, pois desde a sua fundação em 1999, a Pulmoclínica tem cadastrados em seus arquivos cerca de 17.000 pacientes, onde nos períodos de maior movimento são atendidos 502 pacientes/mês, o que representa $2,95 \%$ do total de pacientes cadastrados. Partindo do ponto de sua fundação, houve um incremento de $1,77 \%$ no atendimento, mas em relação a quantidade total de pacientes cadastrados, considere-se relativamente baixo o índice atual apresentado. Com isso a clínica parece não identificar as necessidades dos clientes com clareza, deixando a desejar os contatos atuais, bem como os futuros contatos.

Conforme verificado na pesquisa primária, mais especificamente nas questões um, dois, três, seis, oito e nove, o perfil do cliente/consumidor da clínica é em sua maioria mulheres, com idade acima de 45 anos, que tratam de doença crônica, tem plano de saúde ou convênio com sindicatos e o meio de comunicação mais utilizado é o telefone. Hoje, a utilização da comunicação clínica - cliente é improdutiva, deixando o consumidor em termos, um pouco insatisfeito.

A sugestão de implantação de um Call Center vem de encontro a necessidade constante de buscar e manter os clientes, através de uma oferta diferenciada de produtos e serviços de qualidade. Para implantar um Call Center, é necessário verificar o quanto se está perdendo com a ineficiência do serviço atual e ter bem claro qual é o objetivo do investimento. O termo Call Center pode ser definido como uma convergência de canais de comunicação com o mercado, onde, envolve todos os mecanismos responsáveis pelo gerenciamento de contato através de novas tecnologias, ocorrendo a migração do telemarketing para o Call Center e constituindo-se como uma nova visão na gestão destes canais [1].

No caso da clínica, a criação de um atendimento ativo/receptivo tem como objetivo melhorar a comunicação com os clientes, ampliar a carteira de clientes e aumentar as vendas pelo telefone. A automação do processo de Call Center gera mais segurança, fidelização e possibilita o resgate de clientes.

A escolha da linha telefônica é fundamental, pois se a clínica permanecer com uma linha telefônica convencional, dificilmente o paciente terá interesse em ligar, tendo em vista que o custo da ligação refletiria na sua conta telefônica. Dessa forma, a clínica pode oferecer um serviço gratuito, ou seja, o 0800 , onde a conexão paciente/clínica seria facilitada.

A escolha do software de CRM, neste caso também é fundamental. Um software bem elaborado possibilitaria ao atendente verificar e transmitir informações ao paciente em tempo real. Pesquisado algumas empresas, segue modelo de software que melhor se ajusta para o Call Center na clínica.

Em relação à população estimada de Blumenau, $65 \%$ dessa população possui algum convênio de saúde. Atendimento da clínica em relação a população que possui plano de saúde ou são filiados aos sindicatos: 190.000 total de convênios / 386 atendimentos/mês = $0,20 \%$ (baixa temporada) $0,20 \%$ é a população economicamente ativa com a implantação do Call Center. 190.000 total de convênios / 502 atendimentos $/$ mês $=0,26 \%$ (alta temporada) $0,26 \%$ é a população economicamente ativa com a implantação do Call Center.

O contato realizado pelo atendente treinado, que recebe e faz ligações, através do Call Center, esse centro integrado com recursos de tecnologia que possibilitará criar oportunidades para fidelizar a clientela, impedindo que este migre para a concorrência e também aumentar sua carteira de clientes.

Para obtenção do retorno do investimento em um Call Center, é necessário que a organização estipule metas de vendas ao atendente responsável pelo Call Center e ao vendedor externo, que seriam acompanhados através de relatórios emitidos pelos funcionários envolvidos, aumento da carteira de clientes, bem como o aumento do fluxo de caixa. Para reforçar o cumprimento dessas metas, a empresa deve oferecer premiações a seus vendedores como: meta cumprida durante um período, um percentual incorporaria ao salário, os colaboradores também poderiam ser contemplados com cursos que melhorariam sua qualificação profissional ou até mesmo proporcionar um fim de semana num hotel, pois funcionário motivado trabalha com muito mais afinco.

Parcerias com fornecedores: Todos os fornecedores serão cadastrados, após uma triagem junto aos órgãos da fiscalização da saúde. Essa preocupação se dá em oferecer os melhores produtos para o consumidor final, diminuindo os riscos de contaminação e estabelecendo parcerias de longo prazo. As novas maneira de fazer negócio implicam que as organizações devem se adaptar culturalmente as mudanças, avaliando e implementando suas ações constantemente. Hoje, as novas tecnologias possibilitam muito mais que a simples troca de informações. A integração entre a empresa e o cliente deve ser entendida de maneira mais ampla que deve ser percebida pelo usuário como um facilitador da transferência de dados.

Relativo ao site na Internet: Apresentar e promover produtos e serviços, através da Internet; Formar parcerias com as demais clínicas que comportam o Centro Clínico Santa Catarina, para a troca de e-mails e captação de novos entrantes; Atualizar constantemente o site; Criar um atendimento personalizado, ou seja, cada vez que o usuário acessar a página, será recebido com uma saudação personalizada; Controlar o número de acessos à página da clínica. Uma vez que aconteça a fidelização do cliente consumidor, a clínica deverá programar uma senha de acesso, o que permite um maior controle dos que visitam a página da clínica. Responder aos questionamentos, esclarecer dúvidas com a maior brevidade possível; Criar um blog interativo, com fotos dos eventos, palestras e seminários realizados pela clínica. A mesma metodologia poderá ser utilizada no atendimento prestado à crianças; Criar informativos com dicas de saúde e beleza que devem ser atualizados constantemente; Formar parcerias com as empresas, convênios de saúde e sindicatos, disponibilizando alguns serviços gratuitos, através do e-mail de seus colaboradores; 
Relativo aos meios de comunicação de massa: Conforme a pesquisa realizada, quando indagados qual meio de comunicação facilitaria o aceso dos usuários à Clínica, os respondentes colocaram que a televisão é o que melhor promoveria esse contato, sendo de fundamental importância que a clínica invista em propaganda televisiva.

Relativo a comunicação interna: Para melhor atender seus clientes, a clínica tem como opção manter próximos os serviços, ou seja, compor os departamentos afins no mesmo andar, o que facilitaria o entendimento do cliente quanto ao seu direcionamento e reduziria falhas na comunicação interna;

\section{Discussão e Conclusões}

A utilização da ferramenta gerencial Customer Relationship Management - CRM, possibilita as organizações terem maior conhecimento dos clientes a serem atingidos, estimulando a lealdade do cliente à marca, através de um acompanhamento personalizado, oferecendo-lhes algo mais e evitando sua migração para a concorrência. Da mesma forma que o CRM consegue atingir os clientes dos mais variados níveis sociais, através dos seus canais de comunicação, este módulo utiliza a mesma tecnologia para garantir um acompanhamento efetivo a todas as camadas sociais. Nesta nova estrutura social, ter um bom relacionamento com o cliente, fornecendo o que ele necessita, na hora e local que desejar é uma forma de fidelização e consequentemente aumentar suas vendas. No caso estudado o objetivo geral foi atendido, através do processo de identificação do cliente, levantamento dos anseios e necessidades estava precário, evidenciando a necessidade da empresa em aplicar um programa de Customer Relationship Management - CRM, visando corrigir os diferentes problemas identificados no decorrer do estudo.

$\mathrm{O}$ atendimento em geral da clínica, pode ser considerado de qualidade em alguns aspectos, enquanto que em outros aspectos, é importante aprimorar os serviços no contexto do atendimento, principalmente, por atender maior demanda de pessoas acima de 45 anos. O perfil do cliente consumidor da clínica é em sua maioria do sexo feminino. O grau de escolaridade assemelha-se na quantidade entre os que possuem mais estudo e os que possuem menos estudo, portanto, o atendimento deve ser aprimorado para atender os clientes dessas escalas de escolaridade.

Observou-se que a maioria dos clientes ocupam os serviços da clínica para tratamento de doença crônica. Doença crônica é um problema que atinge atualmente, as diversas camadas sociais. Sendo esse um fator predominante e crescente, tornou-se um importante problema de saúde da humanidade.

É necessário que essas doenças sejam acompanhadas e monitoradas, de forma que o paciente possa aumentar seu tempo de vida, evitando as complicações associadas a essas doenças. Verificou-se que a comunicação entre a empresa e o cliente consumidor, acontece em sua maioria por telefone. Sendo esse o meio de comunicação mais utilizado, a clínica deve buscar o aprimoramento do atendimento nessa área. A implantação de um Call Center, com um profissional atuante e capacitado, forneceria as condições necessárias para o completo entrosamento clínica/cliente consumidor, ou seja, com a implantação do Call Center, a clínica poderá dispensar a seus usuários um tratamento especial, recebendo e retornando as informações em tempo real, criando assim um diferencial competitivo. Além do investimento na montagem de um Call Center, a empresa deve investir em outras áreas, aprimorando o contato com o público, através de alternativas como o lançamento de propaganda. Apontada na pesquisa, pelos consumidores atuais como o meio de comunicação mais utilizado, a televisão é um excelente veículo para estabelecer essa conexão.

Apesar da pouca expressividade apontada na pesquisa, o rádio também pode se transformar em um excelente veículo propagador da clínica. O lançamento de um PROGRAMET, além de todo conhecimento repassado aos usuários, através de suas dicas de saúde, oportuniza a clínica a se tornar mais conhecida do público consumidor. Ainda que na pesquisa a presença de fatores de risco e doenças concomitantes não tenham sido apontados como um fator relevante, pois a maioria dos clientes atuais apresenta um número pouco significativo ou não apresenta nenhum dos tópicos sugeridos, como diabetes, hipertensão, et., é interessante que a clínica mantenha seu banco de dados atualizado, de forma que possa desenvolver mecanismos para oferecer a seus clientes as condições necessárias, tanto no espaço físico e serviços, quanto no atendimento oferecido, tendo em vista que cada cliente é único e espera ser atendido de forma única.

No decorrer do estudo, houve um pouco de resistência no repasse das informações por parte da clínica. Contudo, a implantação de uma nova metodologia de trabalho implica em mudanças, onde na maioria das vezes causa desconforto, mas para que o cliente possa receber a atenção necessária, a organização deve engajar-se como um todo a essas mudanças, portanto, o relacionamento com o cliente ainda é uma incógnita para a saúde, ficando a cargo dos profissionais da área começar a empregar esse relacionamento de forma mais intensa, criando uma personalização, despertando a consciência do cliente para a fidelização.

\section{Referências}

[1] ALECRIM, Emerson. Tecnologia da informação. Disponível em: http://www.infowester.com/col150804.php Acesso em: 15 fev. 2006.

[2] BEAL, Adriana. Segurança de tecnologia de informação. Disponível em: http://www.modulo.com.br/index.jsp?page=3\&cati 
$\mathrm{d}=2$ \&objid $=383$ \&pagecounter $=0$ \&idiom $=0$ 07.06.2004. Acesso em: 16 fev. 2006.

[3] BRETZKE, Míriam. Marketing de relacionamento e competição em tempo real: com CRM (Customer Relashionship Management). São Paulo: Atlas, 2000.

[4] BRETZKE, Míriam. A estratégia de CRM e a gestão empresarial orientada para o cliente. http://www.itcom.com.br/pdf/021016.pdf.24.09.20 01. Acesso em: 29/04/06.

[5] CARMO, Romeu Mendes. Gestão da tecnologia da informação. Disponível e m : http://www.guiarh.com.br/p62.htm. Acesso em: 17 fev. 2006.

[6] CARVAlHO, André de Oliveira. EDUARDO, Maria Bernadete de Paula. Saúde e Cidadania. Sistemas de Informação em Saúde para municípios. São Paulo: Editora Fundação Petrópolis, 1998.

[7] DALFOVO, Oscar. Sistemas de informação: Estudos e casos. Blumenau: Acadêmica, 2004.

[8] DAVENPORT, Thomas H. Ecologia da Informação: porque só a tecnologia não basta para o sucesso na era da informação. São Paulo: FUTURA, 1998.

[9] GRABNER-KRAEUTER,Sonja; MOEDRITSCHER, Gernot. Alternative approacher toward measuring CRM performance 6th. Research Conference on Relashionship Marketing and CRM, Atlanta, 2002.

[10] KINDAM, Christopher. Inteligência competitiva. D i $\quad$ s e $\mathrm{m}$ : $<$ http://conimexbrazil.s2w.com.br/doc/inteligencia_ competitiva.doc. Acesso em 16 fev. 2006.
[11] LEMOS, Paulo. Tecnologia da Informação: Economia e gestão da tecnologia da informação. $\mathrm{D}$ i $\mathrm{s}$ p o n í v e 1 e $\mathrm{m}$ : http://www.revista.unicamp.br/infotec.10.07.2001 Acesso em: 16 fev. 2006.

[12] MARCONI, Marina de Andrade; LAKATOS, Eva Maria. Técnicas de Pesquisa: planejamento e execução de pesquisas, amostragem e técnicas de pesquisas, elaboração, análise e interpretação de dados. 4 ed. São Paulo: ATLAS, 1999.

[13] MINISTÉRIO DA CIÊNCIA E TECNOLOGIA et al. Ciência e Tecnologia para a construção da sociedade da informação. Disponível em http://www.mct.gov.br/Temas/Socinfo/CET.socinf o.pdf. Acesso em: 03 out. 2005.

[14] O’BRIEN, James A . Sistemas de Informação e as decisões gerenciais na era da Internet. São Paulo: SARAIVA, 2003.

[15] PEDRON, Cristiane Drebes, DAMACENA, Cláudio. Aplicação do Costumer Relationship Management (CRM) nas Empresas. http://www.inf.unisinos.br/ cdpedron/artigos/slade 2004.pdf. Acesso em: 01/05/06.

[16] RODRIGUES, Leonel Cezar. Estratégias tecnológicas como recurso competitivo do setor têxtil da região de Blumenau. Revista de Negócios, Blumenau: v.1, n.3, p. 13-30, abr./jun. 1996.

[17] STAIR, Ralph M.; REYNOLDS George W. Princípios de Sistemas de Informação. 4 ed. Rio de Janeiro: LTC Editora AS, 2002. 